ISSN: 2316-6517

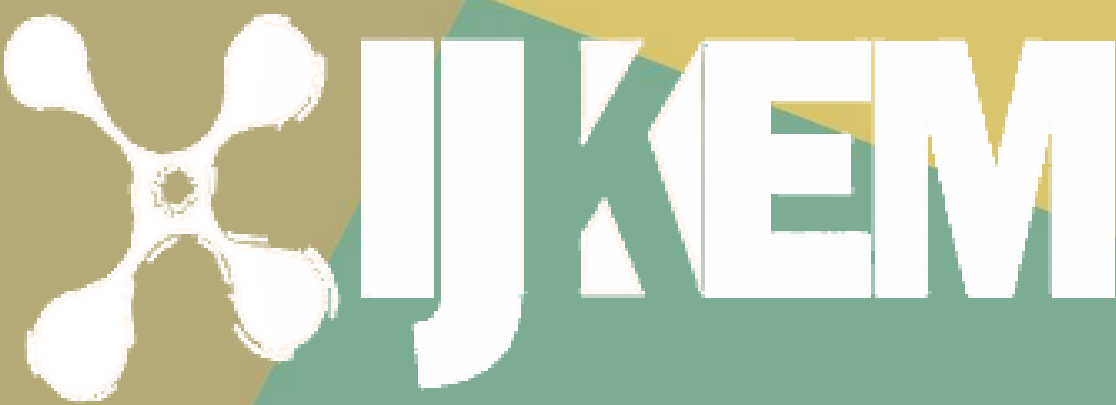

International Journal of Knowledge Engineering and Management

$$
\text { v. } 9, \text { n. } 25,2020 .
$$

(c) (1) \$

jjkem.ufsc.br 
International Journal of Knowledge Engineering and Management,

Florianópolis, v. 9, n. 25, p.93 - 126, 2020.

- ISSN 2316-6517 •

- DOI: 1047916 •

\title{
INFLUENCE FACTORS OF THE TACIT KNOWLEDGE ELICITATION PROCESS: SYSTEMATIC LITERATURE REVIEW
}

\begin{abstract}
CLÁUDIO ROBERTO DO ROSÁRIO
Doutorando, Programa de Pós-Graduação em Engenharia de Produção da

Universidade Federal do Rio Grande do Sul (UFRGS)

claudio.rosario@univates.br

ORCID: https://orcid.org/0000-0002-7548-3380

FERNANDO GONÇALVES AMARAL

Doutor, Université Catholique de Louvain (UCL)

Universidade Federal do Rio Grande do Sul (UFRGS)

amaral@producao.ufrgs.br

ORCID: https://orcid.org/0000-0003-4581-9557
\end{abstract}

Submissão: 10/08/21 Aceitação: 01/09/21

Sistema de avaliação: duplo cego (double blind review).

UNIVERSIDADE FEDERAL DE SANTA CATARINA (UFSC)

(ㄷ) (1) (ㅇ) 


\section{INFLUENCE FACTORS OF THE TACIT KNOWLEDGE ELICITATION PROCESS: SYSTEMATIC LITERATURE REVIEW}

\section{Abstract}

Goal: This systematic review aimed at highlighting and performing an integrated discussion of the factors of the tacit knowledge elicitation process.

Design|Methodology|Approach: The research method adopted in this study was (PRISMA) Preferred Reporting Items for Systematic Reviews and Meta-Analyses. The databases, Science Direct, Web of Science, Scopus and Emerald Insight were chosen based on the possibility of finding articles from collections such as: Elsevier, Springer e Taylor \& Francis. Search terms related to "knowledge Elicitation" are the following: "knowledge Elicitation" OR "knowledge acquisition" AND technique AND "Tacit Knowledge".

Results: The main research findings listed by the article were the inclusion of a knowledge engineer considering the SECI model, the indication of predictability in the perception of episodic knowledge in a tacit knowledge elicitation process and the hybrid adoption of knowledge elicitation techniques.

Limitations of the research: The selection criteria were based only on articles written in the English language and taking into consideration the period from 2008 to 2020.

Originality |value: The structure of this article was based on the indication of theoretical gaps and the need to deepen the themes underlying the process of eliciting tacit knowledge, which allowed a systematic exposure of a broad a scenario that represents the scope and complexity.

Palavra-chave: Knowledge elicitation. Tacit knowledge. Elicitation techniques. 
Florianópolis, v. 9, n. 25, p.93 - 126, 2020.

- ISSN 2316-6517 •

- DOI: 1047916 •

\section{FATORES INFLUENTES DO PROCESSO DE ELICITAÇÃO DO CONHECIMENTO TÁCITO: UMA REVISÃO SISTEMÁTICA DA LITERATURA}

\section{Resumo}

Objetivo: Esta revisão sistemática teve como objetivo destacar e realizar uma discussão integrada dos fatores do processo de elicitação do conhecimento tácito.

Design|Metodologia|Abordagem: O método de pesquisa adotado neste estudo foi (PRISMA) Preferred Reporting Items for Systematic Reviews and Meta-Analyses. As bases de dados Science Direct, Web of Science, Scopus e Emerald Insight foram escolhidas com base na possibilidade de encontrar artigos de coleções como: Elsevier, Springer e Taylor \& Francis. Os termos de pesquisa relacionados a "Elicitação de conhecimento" são os seguintes: "Elicitação de conhecimento" OU "aquisição de conhecimento" AND técnica AND "Conhecimento tácito".

Resultados: Os principais achados de pesquisa elencados pelo artigo foram a inclusão de um engenheiro do conhecimento considerando o modelo SECI, a indicação de previsibilidade na percepção do conhecimento episódico em um processo de elicitação de conhecimento tácito e a adoção híbrida de técnicas de elicitação de conhecimento.

Limitações da pesquisa: Os critérios de seleção foram baseados apenas em artigos escritos na língua inglesa e levando em consideração o período de 2008 a 2020.

Originalidade |valor: A estruturação deste artigo baseou-se na indicação de lacunas teóricas e na necessidade de aprofundamento das temáticas subjacentes ao processo de elicitação do conhecimento tácito, o que permitiu a exposição sistemática de um cenário amplo que representa a abrangência e a complexidade.

Keywords: Elicitação de conhecimento. Conhecimento tácito. Técnicas de elicitação. 


\section{International Journal of Knowledge Engineering and Management,}

Florianópolis, v. 9, n. 25, p.93 - 126, 2020.

- ISSN 2316-6517 •

- DOI: 1047916 •

\section{Introduction}

Tacit knowledge can be understood as the practical way to know how to perform some activity. The term is not limited only to a category of knowledge, but to a process of building skills, competencies and rationalities Oguz and Elif (2011). Studies on tacit knowledge began in Polanyi (1966), especially regarding the dimension of this kind of knowledge. Subsequently, Nonaka (1991) and Nonaka and Takeuchi (1995), disseminated the concepts of tacit knowledge, relating it to the process of conversion to explicit knowledge for the purpose of promoting organizational learning, the process of conversion, according to Zhou (2004) and Flanagan and Clarkson (2007), beginning with the understanding of the cognitive process of knowledge holders.

Nonaka (1994), Nonaka, Byosiere and Borucki (1994), Nonaka, Umemoto and Senoo (1996) and Nonaka and Von Krogh (2009) contributed to Polanyi's thesis by focusing on the theory of knowledge creation, instituting the four stages of conversion of tacit knowledge to explicit, i) Socialization, ii) Externalization, iii) Combination and iv) Internalization, represented by the SECI model. Through the four phases, knowledge is transformed from individual epistemological tacit to explicit organizational ontological. However, Gavrilova and Andreeva (2012) point to limitations in the Externalization phase, indicating research opportunities to explore this phase of knowledge conversion. In this sense, the authors stimulate the scientific community when they pose the following question, "Externalization, how to achieve it?". One of the mechanisms adopted by the scientific community to promote the conversion of tacit knowledge into explicit knowledge are the tactics of eliciting tacit knowledge Rosário et al. (2015); Hao et al. (2017).

Gàbor and Barna (1988) and Wagne, Otto and Chung (2002) indicate that knowledge elicitation is the main activity in the management of Knowledge Based Systems (KBS). In this context, Ulrich (2004), Li Dacheng and Jinji Gao (2010), Garg, Monica, Sharma and Yashi (2014), Liu, Jian-Xin, Xiao-Jun and Ging-lian (2014), Oliva, Medina, Weber and Jung (2015) recognize the importance of human knowledge as part of the systems modeling process developed to promote greater process reliability.

Knowledge mapping, as exemplified in Margaryan, Littlejohn and Stanton (2016), consists of the development of mechanisms that comprise tacit practices. In a macro context, they have a multidisciplinary approach involving elements such as 


\section{International Journal of Knowledge Engineering and Management,}

Florianópolis, v. 9, n. 25, p.93 - 126, 2020.

- ISSN 2316-6517 •

- DOI: 1047916 •

organizational structure, cultural factors, technologies and human resources Ebrahim (2006), Sasson and lan (2006) and Plessis (2007). For Coffey and Hoffman (2003) and Garcia-Perez, Shaikh, Kalutarage and Jahantab (2015), through knowledge modeling it is possible to represent a complex system and the decision making inherent in that system. Finally, Nikulina and Khomenko (2015) mention that cognition management is a more productive way to help understand what is done to represent the best way to do it. Thus, the elicitation of tacit knowledge becomes an important element to be researched in a context involving Knowledge Based Systems (KBS), (Cairó \& Guardati, 2012).

The theme of this systematic review was to address the factors of the tacit knowledge elicitation process, based on indications of the need for theoretical deepening the topic found, for example, in Hoffman (2008), Abdul-Rahman, Wang and Siong (2011), Gavrilova and Andreeva (2012), Krishna and Busch (2012), Vásquez-Bravo, Segura, Domínguez and Amescua (2014), Rosario et al. (2015).

Hao et al. (2017) explore the factors of the process of knowledge elicitation, but without discussing them in an integrated manner. Thus, this study aims to contribute to a greater understanding of the subject through the analysis and synthesis of previously defined research topics. In addition, it seeks to highlight future research opportunities, as well as propose theoretical support for research in an empirical context. The following research questions are formulated to address this objective:

Research Question 1: "How is the state-of-the-art around the influence factors of the process of converting tacit to explicit knowledge from 2008 to 2020?"

Research Question 2: "What are the future empirical research directions regarding the adoption of tacit knowledge elicitation techniques?"

\subsection{Investigation topics}

The section aims to establish some research topics underlying the research questions. Research topics are the factors that involve the process of eliciting tacit knowledge. In his research on the first essays towards the knowledge elicitation process, Hoffman (2008) addressed some points that were used as parameters to establish the first research topics that are related to the knowledge elicitation process, such as: Type 


\title{
International Journal of Knowledge Engineering and Management,
}

\author{
Florianópolis, v. 9, n. 25, p.93 - 126, 2020. \\ -ISSN 2316-6517 • \\ - DOI: 1047916 •
}

of interview with knowledge holder, Types of knowledge (declarative, procedural, and episodic) and Elicitation of individual and collective knowledge.

Regarding the interview with the knowledge holder, Gavrilova and Andreeva (2012) propose a special agent (analyst) to facilitate the process of knowledge elicitation. Evidence of practical use of the agent has already been studied and can be found in studies such as Rosário et al. (2015). According to the authors, the agent is called the Knowledge Engineer and thus established the fourth research topic: Evidencing the indications of a Knowledge Engineer as a facilitator of the tacit knowledge elicitation process.

The studies of Polanyi (1966,) show the dimension of tacit knowledge and the human limitations expected of a Knowledge Engineer, given the fact that the real dimension of human knowledge is limited to the ability to verbalize the knowledge in its entirety. Based on its premises, one of the challenges of this research arises, that is, to investigate the trends of the development of mechanisms that may be useful to deal with the difficulty of verbalizing knowledge. To this end, it becomes relevant to analyze the paradigm of the dimension of tacit knowledge thus establishing the fifth topic of investigation.

In this scope, knowledge elicitation techniques are adopted to assist in the process of knowledge reuse and, as a consequence, promote organizational learning Preiss (2000), Kwong and Lee (2009) and Whyte and Classen (2012). For Hao Jia et al. (2017) knowledge elicitation techniques are adopted as a mechanism for the conversion of tacit knowledge to explicit knowledge, which can be adopted by the Knowledge Engineer as a way to maximize results in a process of elicitation of knowledge. However, what have been the recent trends in adopting these techniques? The sixth research topic addresses trends in the adoption of tacit knowledge elicitation techniques. For example, Hao Jia et al. (2017) indicate the Repertory Grid technique as an emerging alternative for eliciting tacit knowledge based on Abdul-Rahman, Wang and Siong (2011). When studying trends in the adoption of knowledge elicitation techniques, the scope of the techniques is an aspect to be considered. This review adopted the premise of VásquezBravo et. al. (2014) in which the process of knowledge elicitation comprises three phases: $1^{\text {st }}$ ) acquisition, $2^{\text {nd }}$ ) representation and $3^{\text {rd }}$ ) knowledge transfer. From this perspective, the authors Gavrilova and Andreeva (2012) and Vásquez-Bravo et al. (2014) indicate the importance of merging knowledge elicitation techniques, given their 


\section{International Journal of Knowledge Engineering and Management,}

Florianópolis, v. 9, n. 25, p.93 - 126, 2020.

- ISSN 2316-6517 •

- DOI: 1047916 •

limitations when adopted exclusively. Therefore, it is possible to promote complementarity between the techniques in promoting knowledge management. Hao Jia et al. (2017) complement this view by indicating the possibility of adopting hybrid methods for the process of eliciting tacit knowledge by stating that, "To study hybrid methods for tacit knowledge extraction, because the combination of multiple methods has the potential to overcome the disadvantages of a single method, Hao Jia et al. (2017)".

However, it is understood that a systematic analysis of the trends in the adoption of tacit knowledge elicitation techniques is necessary in order to further highlight the scientific indications around this theme. Figure 1 represents the relationship between research question I and II and contextualized research topics. Table 1 represents the summary of the research topics underlying the research questions.

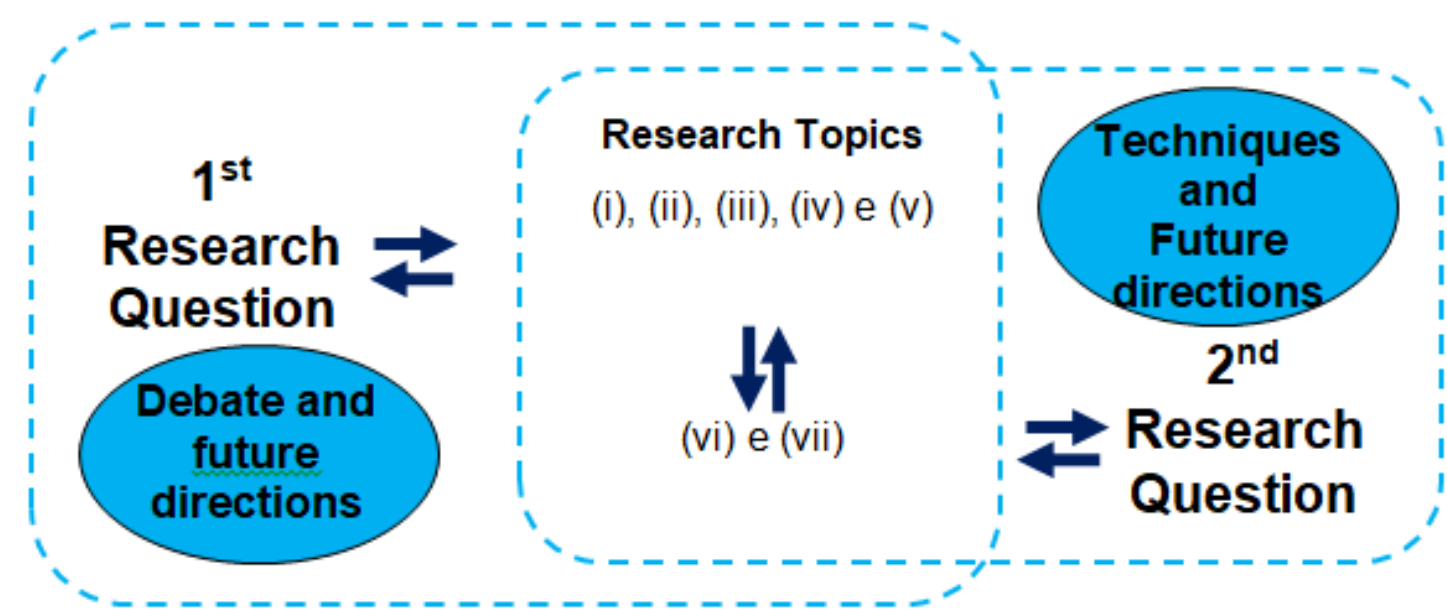

Figure 1 - Relation between research topics and research questions. Source: Authors

Table 1 - Research topics (2021).

\begin{tabular}{|c|l|c|}
\hline${ }^{*} R Q$ & \multicolumn{1}{|c|}{ Research Topics } & Sources \\
\hline $\mathbf{1}$ & $\begin{array}{l}\text { (i) Interview type; } \\
\text { (ii) Knowledge type, (declarative, procedural); } \\
\text { (iii) Elicitation of individual and collective } \\
\text { knowledge. }\end{array}$ & (Hoffman, 2008) \\
\hline
\end{tabular}




\begin{tabular}{|c|c|c|}
\hline & $\begin{array}{l}\text { (iv) Highlight the nominations of a Knowledge } \\
\text { Engineer as a facilitator of the tacit knowledge } \\
\text { elicitation process. }\end{array}$ & $\begin{array}{l}\text { (Gavrilova and Andreeva, } \\
\text { 2012) and (Rosário et al. } \\
\text { 2015) }\end{array}$ \\
\hline & $\begin{array}{l}\text { (v) Analysis of the indications of quotations from } \\
\text { (Polanyi, 1966) in relation to the paradigm of the } \\
\text { tacit knowledge elicitation dimension. }\end{array}$ & (Polanyi, 1966) \\
\hline \multirow[b]{2}{*}{2} & $\begin{array}{l}\text { (vi) Systematic analysis of trends in the adoption } \\
\text { of tacit knowledge elicitation techniques. }\end{array}$ & $\begin{array}{l}\text { (Hao et al., 2017), (Abdul- } \\
\text { Rahman, Wang and Siong, } \\
\text { 2011). }\end{array}$ \\
\hline & $\begin{array}{l}\text { (vii) To analyze the indications of knowledge } \\
\text { elicitation techniques, with a view to their } \\
\text { complementary aspects or hybrid adoption. }\end{array}$ & $\begin{array}{c}\text { (Gavrilova and Andreeva, } \\
\text { 2012), (Vásquez-Bravo et } \\
\text { al., 2014) and } \\
\text { (Hao Jia et al.,2017) }\end{array}$ \\
\hline
\end{tabular}

Source: Authors (2021)

\section{Methodology}

According to Boell and Kecmanovic (2015) and Templier and Pare (2015), the first step in planning a rigorous Systematic Literature Review (SLR) is the formulation of research questions, as they will be responsible for directing the research protocol. To this end, the introductory section contextualized the theme and established the research questions. The protocol adopted in this study was PRISMA (Preferred Reporting Items for Systematic Reviews and Meta-Analyses), indicated by Moher, Eastwood, Rennie and Stroup (1999; 2009), in order to reduce the possibility of inconsistency in conducting the investigation. According to Moher et al. (2009), PRISMA consists of four phases to guide the development of the research protocol, $1^{\text {st }}$ ) database identification, $2^{\text {nd }}$ ) screening, $3^{\text {rd }}$ ) eligibility and $4^{\text {th }}$ ) inclusion criteria.

The databases, Science Direct, Web of Science, Scopus and Emerald Insight were chosen based on the possibility of finding articles from collections such as: Elsevier, Springer e Taylor \& Francis. Search terms related to "knowledge Elicitation" are the following: "knowledge Elicitation" OR "knowledge acquisition" AND technique AND "Tacit Knowledge".

The selection criteria were based only on articles written in the English language and taking into consideration the period from 2008 to 2020. The choice of the starting date of the literature review period coincides with the studies of Hoffman (2008), 


\section{International Journal of Knowledge Engineering and Management,}

Florianópolis, v. 9, n. 25, p.93 - 126, 2020.

- ISSN 2316-6517 •

- DOI: 1047916 •

establishing the first research topics in relation to the process of knowledge elicitation. We selected the first ten articles, listed by database, by search term, based on the relevance criteria of each database.

After the initial search, duplicity between the articles was analyzed. The eligibility criteria selected were articles from journals covered in JRC 2020 (Journal Citation Reports). For the inclusion criteria of previously validated articles, it was decided to analyze the abstract looking for a relationship with the research questions. The analysis was performed by two researchers with experience and knowledge of the central theme of the study and the inclusion criteria were:

$\checkmark 1^{\text {st }}$ Approach to tacit knowledge as the central theme of the research;

$\checkmark 2^{\text {nd }}$ Focus on techniques of knowledge elicitation.

The number of articles selected in each step of the protocol is represented by Figure 2. 


\section{International Journal of Knowledge Engineering and Management,}

Florianópolis, v. 9, n. 25, p.93 - 126, 2020.

- ISSN 2316-6517 •

-DOI: 1047916 •

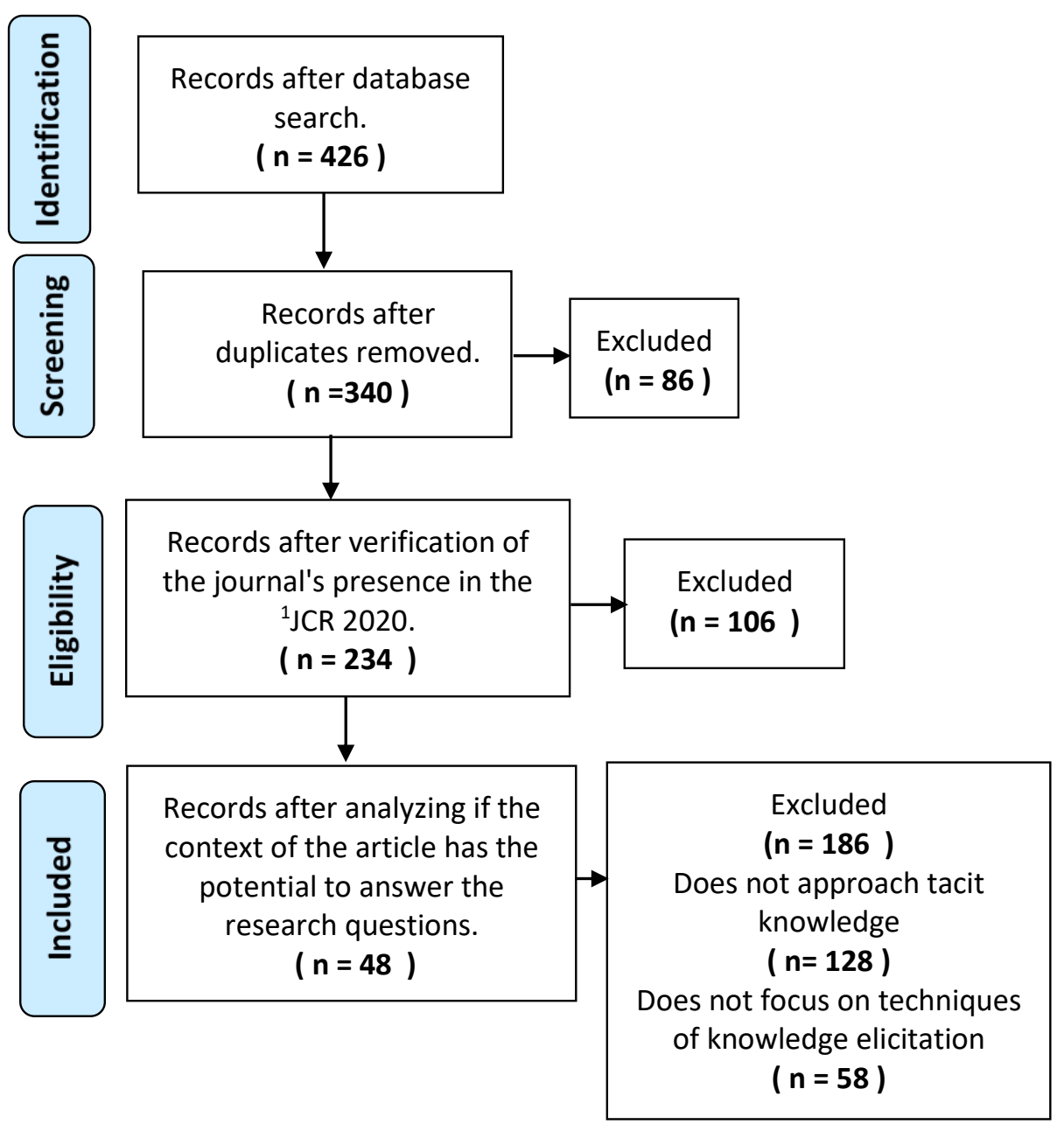

Figure 2 - Results of PRISMA protocol application. Source: Authors (2021). 
International Journal of Knowledge Engineering and Management,

Florianópolis, v. 9, n. 25, p.93 - 126, 2020.

- ISSN 2316-6517 •

-DOI: $1047916 \cdot$

\section{Results}

\subsection{Descriptive Bibliometric Analysis}

Figure 3 represents a chronological overview of research involving tacit knowledge elicitation techniques, given the inclusion criteria adopted by the PRISMA protocol. It has been observed that the central theme of systematic review is present in the literature.

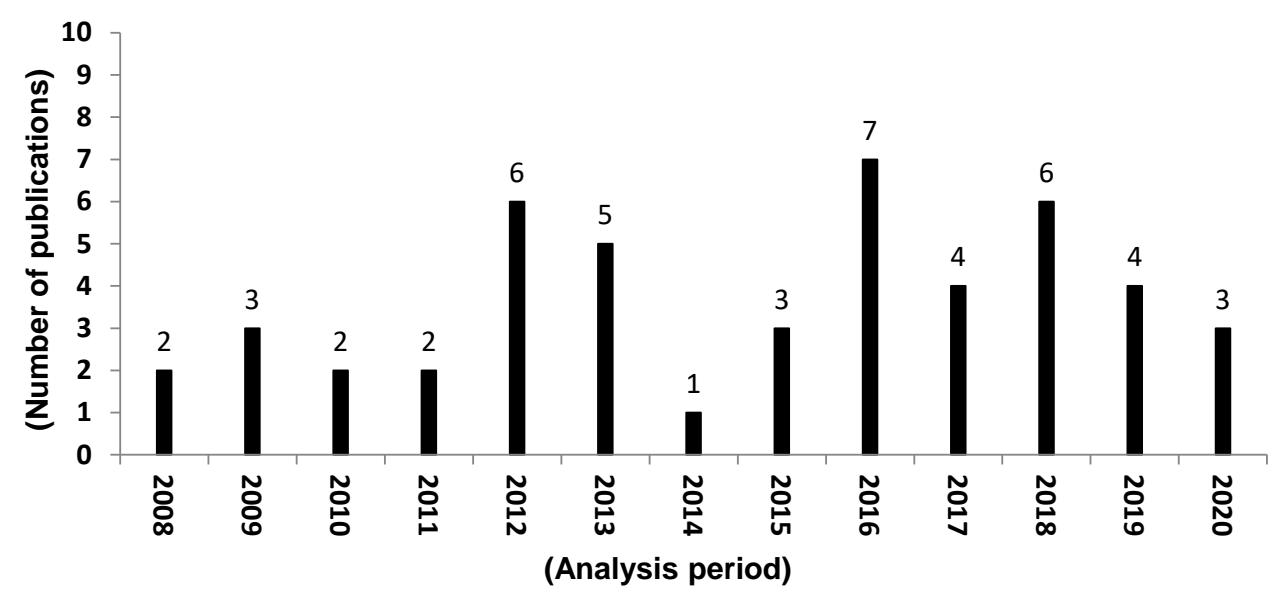

Figure 3 - Publications on tacit knowledge elicitation techniques per year. Source: Authors (2021).

Figure 4 is designed to highlight discussion forums on the central theme of the review from 2008 to June 2020. The three most frequently adopted Journals are: Journal Expert Systems with Applications, Journal of Knowledge Management and International Journal of Human Computer Studies, totaling 20 articles, representing $41.7 \%$ of the articles selected for analysis. 


\section{International Journal of Knowledge Engineering and Management,}

Florianópolis, v. 9, n. 25, p.93 - 126, 2020.

-ISSN 2316-6517 •

- DOI: 1047916 •

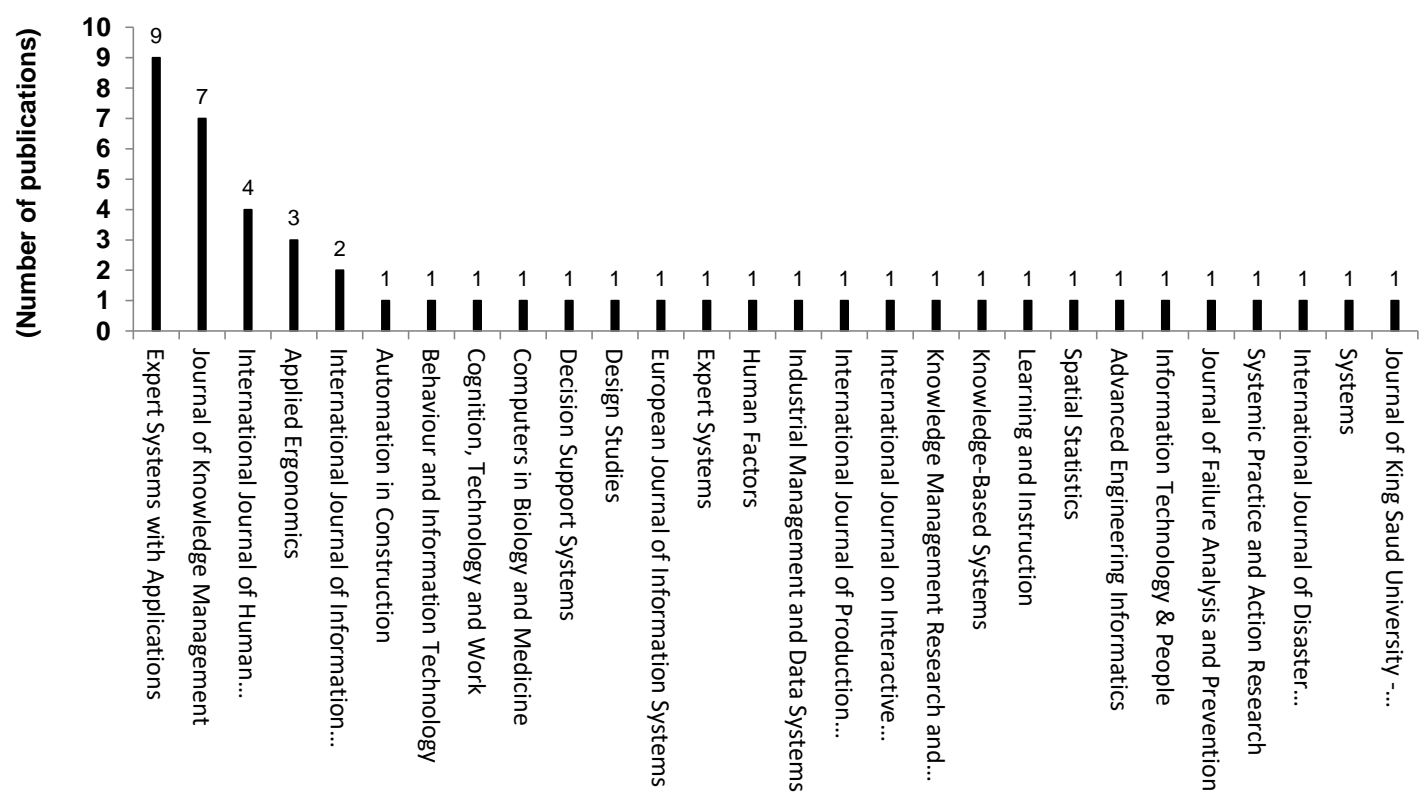

Figure 4 - Publications on tacit knowledge elicitation techniques and journals.

Source: Authors (2021)

\subsection{Factors of the tacit knowledge elicitation process}

As represented by Figure 1, the research topics are factors underlying the research questions, which represent the process of eliciting tacit knowledge. Following are the debates highlighted in the literature surrounding the topics with emphasis on the first research question.

It is observed that the process of eliciting tacit knowledge can be conducted through the following interviews: Semi-Structured, Structured and Unstructured regarding the type of interview, the first research topic. Table 2 represents the indications in the form of citations of the authors regarding interviewing practices in a context of tacit knowledge elicitation. 


\section{International Journal of Knowledge Engineering and Management,}

Florianópolis, v. 9, n. 25, p.93 - 126, 2020.

- ISSN 2316-6517 •

- DOI: 1047916 •

Table 2 - Interview types

\begin{tabular}{|c|c|c|c|}
\hline \multirow[b]{2}{*}{ Sources } & \multicolumn{3}{|c|}{ Interviews Types } \\
\hline & 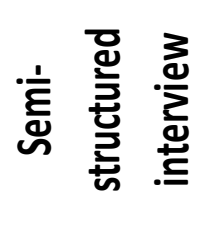 & 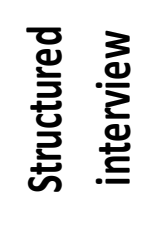 & 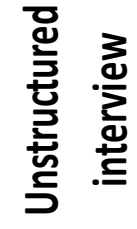 \\
\hline \multicolumn{4}{|l|}{ Hoffman, 2008} \\
\hline \multicolumn{4}{|c|}{ Berge et al., 2008} \\
\hline \multicolumn{4}{|c|}{ Abdul-Rahman, Wang and Siong, 2011} \\
\hline \multicolumn{4}{|c|}{ Selwyn and Classen, 2012} \\
\hline \multicolumn{4}{|l|}{ Xavier et al., 2013} \\
\hline \multicolumn{4}{|l|}{ Rosário et al. 2015} \\
\hline \multicolumn{4}{|l|}{ Durso, Kazi and Ferguson, 2015} \\
\hline \multicolumn{4}{|l|}{ Yip and Lee, 2016} \\
\hline \multicolumn{4}{|c|}{ Leu and Abbass, 2016} \\
\hline \multicolumn{4}{|c|}{ Pattarawan, Brian and Jignya, 2016} \\
\hline \multirow{2}{*}{\multicolumn{4}{|c|}{ Grandvallet et al. 2017}} \\
\hline \multicolumn{2}{|l|}{ Cerchione and Esposito, 2017} & & \\
\hline \multicolumn{4}{|l|}{ Rosso et al., 2018} \\
\hline \multicolumn{4}{|l|}{ Hobballah, et al. 2018} \\
\hline \multicolumn{4}{|l|}{ Laksch and Borsato, 2019} \\
\hline \multicolumn{4}{|l|}{ Okoli J. 2020} \\
\hline Chergui, Zidat and Marir, 2020 & & & \\
\hline
\end{tabular}

Source: Authors (2021).

Understanding how the scientific community approaches the types of knowledge is important to establish the theoretical framework and direct future research. In this context, Xavier et al. (2013) report three types of knowledge: procedural, declarative and episodic. For Pattarawan, Brian and Patel (2016) and Rosso et al. (2018), tacit knowledge is a type of knowledge framed as procedural, in which it relates to action with the way the activity is performed. Xavier et. al. (2013) indicate that procedural knowledge can be framed as specific related to skill and psychomotor activity. Procedural knowledge was related to tacit knowledge in the work of Ting, Wang and Tse (2011) in Health Care, Yip and Lee, (2017) and Grandvallet, Pourroy, Prudhomme and Vignat (2017) in the manufacturing industry. Declarative knowledge is related to the facts that drive actions Leyer, Schneider and Claus (2016) and Pattarawan, Brian and Patel (2016). Declarative 


\section{International Journal of Knowledge Engineering and Management,}

Florianópolis, v. 9, n. 25, p.93 - 126, 2020.

- ISSN 2316-6517 •

- DOI: 1047916 •

knowledge fits in as short-term memory. Also according to Xavier et al. (2013), episodic knowledge is related to long-term memory. As a convergence of ideas Leu and Abbass (2016) and Leyer, Schneider and Claus (2016), they indicate that human cognition represents the interaction of the aforementioned types of knowledge.

By inducing the knowledge holder to report episodic memories, one can identify characteristic elements of long-term memory, Brown, Bruza, Heard, Mengersen and Murray (2016). Furthermore, the authors report that the knowledge holder (expert) has the ability to retrieve episodic memories at a higher level than a non-specialist. This is attributed to the lack or little experience of the non-specialist, which implies dependence on short-term memory, since the non-specialist has limited episodic memory. According to Feldon, Franco, Chao, Peugh and Maahs-Fladung (2018), the expert manipulates both memory types, short and long-term memory. Short-term memory acts as the driving force of long-term memory, and episodic memory works as a link in this context. Establishing elements that can identify the presence of episodic memory in a process of knowledge elicitation may imply the quality of knowledge modeling, as it may assist in the selection of the expert, the knowledge holder (Brown et al., 2016).

The classification of the elicitation of knowledge as individual and collective, third research topic, can help in the process of identification of the elicitation technique and the researcher's objective. Table 3 lists such applications. 


\section{International Journal of Knowledge Engineering and Management,}

Florianópolis, v. 9, n. 25, p.93 - 126, 2020.

- ISSN 2316-6517 •

- DOI: 1047916 •

Table 3 - Individual and colletive elicitation

\begin{tabular}{|c|c|c|c|}
\hline \multirow{2}{*}{ Sources } & \multirow{2}{*}{ Technique } & \multicolumn{2}{|c|}{ Elicitation } \\
\hline & & Individual & Collective \\
\hline \multirow{2}{*}{ Kwong and Lee, 2009} & Cognitive mapping & & \\
\hline & Aggregate cognitive map & & \\
\hline Léger and Naud, 2009 & Statechart diagram & & \\
\hline Tan et al., 2010 & Delphi method & & \\
\hline Zappavigna and Patrick, 2010 & Systemic Functional Linguistics & & \\
\hline Ting et al., 2011 & Concept map & & \\
\hline \multirow{2}{*}{ Abdul-Rahman, Wang e Siong, 2011} & Repertory grid & & \\
\hline & Cluster analysis & & \\
\hline Xavier et al., 2013 & CommonKADS & & \\
\hline Durso, Kazi and Ferguson, 2015 & Cognitive Work Analysis (CWA) & & \\
\hline \multirow{3}{*}{ Rosário et al. 2015} & Card sorting & & \\
\hline & Protocol analysi & & \\
\hline & Observation & & \\
\hline Durso, Kazi and Ferguson, 2015 & Unstructured interview & & \\
\hline Pattarawan, Brian and Jignya, 2016 & Storytelling & & \\
\hline \multirow{2}{*}{ Yip and Lee, 2016} & Unstructured interview & & \\
\hline & Sensemaking & & \\
\hline \multirow{2}{*}{ Grandvallet et al. 2017} & Semi- structured interview & & \\
\hline & Limited information & & \\
\hline Earl, Mavin, and Kassandra, 2017 & Talk-aloud protocols & & \\
\hline \multirow{2}{*}{ Rosso et al., 2018} & Critical Decision Method & & \\
\hline & Hierarchical Task Analysis & & \\
\hline Akhavan, Shahabipour and Hosnavi, 2018 & Cognitive maps & & \\
\hline Hanafizadeh and Ghamkhari, 2019 & Card sorting & & \\
\hline
\end{tabular}

Source: Authors (2021)

Regarding the mechanism that enhances the results of knowledge elicitation, the role of the knowledge engineer as the fourth research topic was highlighted. In this context, there were indications such as: an agent with ability to model mental patterns (Berge et al., 2008), problem modeling (Compton, 2013; Akhavan, Shahabipour \& Hosnavi, 2018), a mediator (Léger \& Naud, 2009) and the need for communication skills (Xavier et al., 2013).

Given the indications of socialization practices between knowledge holders and the knowledge engineer, it is inferred that socialization, the first phase of the SECI model (Nonaka \& Takeuchi, 1995), can be articulated based on the planned approximation of the two agents, which positively influences the externalization phase, since it will be the 


\section{International Journal of Knowledge Engineering and Management,}

Florianópolis, v. 9, n. 25, p.93 - 126, 2020.

- ISSN 2316-6517 •

- DOI: 1047916 •

knowledge engineer who is responsible for making the knowledge explicit in a structured way. The authors Zhang et al. (2009) and Alonso, Martínez, Pérez and Valente (2012) indicate the importance of the need for mutual collaboration between them. Finally, Leu and Abbass (2016) indicate that the knowledge engineer must observe the domain to be modeled before formal socialization with the knowledge holder.

The dimension of tacit knowledge, the fifth research topic, is a challenging theme in a process of knowledge elicitation. The premise under analysis deals with the concept instituted by Polanyi (1966). Overall, the scientific community that addresses knowledge management remains respectful of the tacit knowledge dimension as a Polanyi paradigm. For example, Selwyn and Classen (2012), Pattarawan, Brian and Jignya (2016) and Grandvallet et al. (2017) mention that tacit knowledge is difficult to formalize and communicate. Pattarawan, Brian and Jignya (2016) state that they do not oppose the paradigm, considering that there are limitations regarding the process of eliciting tacit knowledge in its entirety. Other authors such as Mohamed, Chakraborty and Dehlinger (2016), Yip and Lee (2017), Centobelli, Cerchione and Esposito (2018) and Brösamle and Hölscher (2018), cite Polanyi as a reference to a context that addresses knowledge without considering the aspects related to the dimension of tacit knowledge and its characteristics. Therefore, as a contribution, it has been chosen to analyze the characteristics of tacit knowledge reported by Selwyn and Classen (2012), Rosário et al. (2015), Pattarawan, Brian and Jignya, (2016) and Rosso et al. (2018). The citations of the characteristics of tacit knowledge based on Polanyi are summarized by Table 4, observing a convergence in relation to the characteristic of tacit knowledge, intuition, schemas, perspectives, beliefs, procedural and cognitive dimension. 


\section{International Journal of Knowledge Engineering and Management,}

Florianópolis, v. 9, n. 25, p.93 - 126, 2020.

-ISSN 2316-6517 •

- DOI: 1047916 •

Table 4 - Characteristics of tacit knowledge based on Polany (1966)

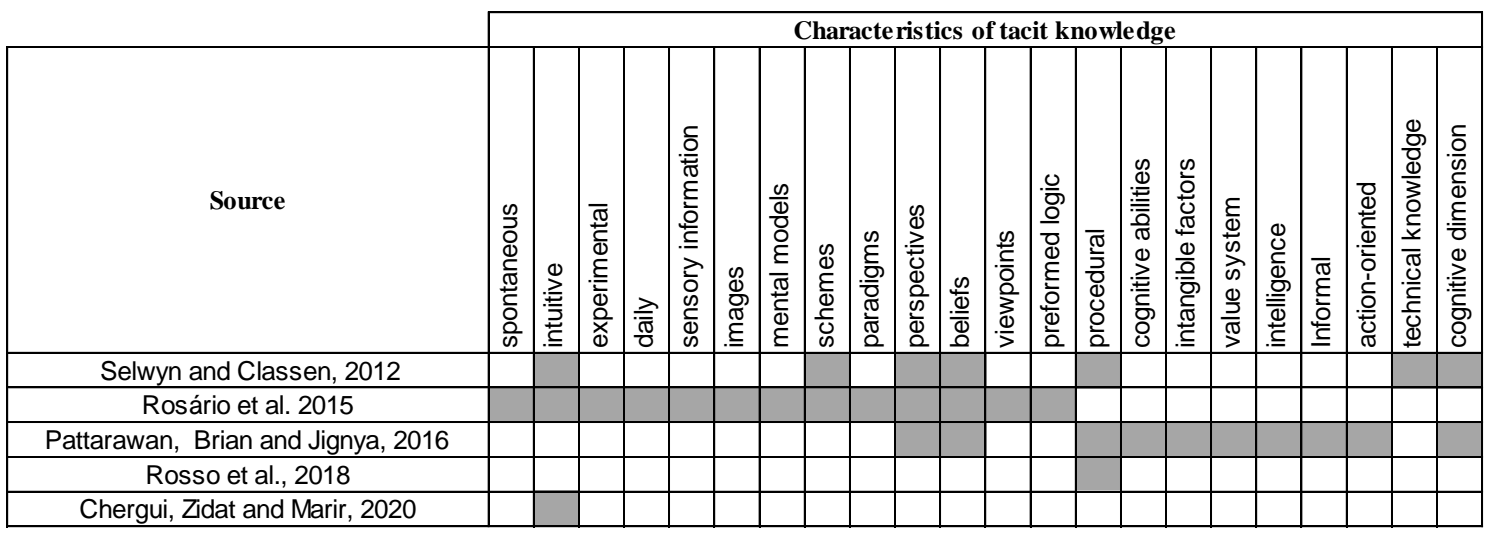

Source: Authors (2021)

Regarding the use of tacit knowledge elicitation techniques, Zappavigna and Patrick (2010) state that they remained problematic from the perspective of the dimension of extracted knowledge. However, the prevalence of Polanyi's premise is observed, due to the lack of studies that direct actions to investigate the dimension of tacit knowledge.

Only one survey found a counterpoint to Polanyi's premise. The authors, Zappavigna and Patrick (2010), state that Polanyi (1966) 's maxim,' We know more than we can say ', remains the dominant perspective in the literature regarding the assumption that tacit knowledge cannot be articulated and transmitted. However, Zappavigna and Patrick (2010) state that linguistic theory may be a counterpoint to Polanyi's premise. The research deepens the study in relation to the meaning of the term "saying", integrating the areas of linguistic theory and information systems. In this study, tacit knowledge was extracted through a grammar-oriented interview method, the Grammartargeted Interview Method (GIM), adopting systemic functional linguistics as a way of analyzing real time conversations. Zappavigna and Patrick (2010) propose an extension to Polanyi's model. "Knowledge can be" codified "in spoken speech because of the linguistic pattern employed in verbalization." The codification of verbalization from the point of view of linguistics and the information system, in turn, helps in the perception of the acquisition of tacit knowledge, and points a way for rediscussion in relation to Polanyi's paradigm. 


\section{International Journal of Knowledge Engineering and Management,}

Florianópolis, v. 9, n. 25, p.93 - 126, 2020.

- ISSN 2316-6517 •

- DOI: 1047916 •

\subsection{Trend of adoption of Tacit Knowledge Elicitation Techniques}

Tacit knowledge elicitation techniques comprise one of the main factors explored by the review. The second research question deals with trend analysis in the adoption of techniques. To this end, the sixth and seventh research topics were established as shown in Figure 1. The research question stems from: "What are future empirical research directions regarding the adoption of tacit knowledge elicitation techniques?"

The techniques found during the literature review are presented in Table 5 . It is structured to represent the sources, techniques or methods, temporal analysis of citations (chronology), number of citations, classification in relation to the phases of the knowledge elicitation process, and the ranking of citations. The phases of the knowledge elicitation process for the study context were classified based on Vásquez-Bravo et al. (2014), which comprises the phases of Acquisition (A), Representation (R) and Knowledge Transfer $(\mathrm{T})$.

The descriptions of each phase were considered for the classification of knowledge elicitation techniques. In the phase of knowledge acquisition (A) there is socialization between the holder and the receiver of the knowledge. Representation (R) deals with the phase in which the inference and modeling of knowledge acquired through a platform corresponding to the reality of the environment in which the knowledge is inserted is promoted. Finally, the knowledge transfer phase $(\mathrm{T})$ has the role of transmitting knowledge, that is, the way in which knowledge holders make decisions. 


\title{
International Journal of Knowledge Engineering and Management,
}

\author{
Florianópolis, v. 9, n. 25, p.93 - 126, 2020. \\ - ISSN 2316-6517 • \\ - DOI: 1047916 •
}

Table 5 - Analysis of the trend of indications in the adoption of Tacit Knowledge Elicitation Techniques

\begin{tabular}{|c|c|c|c|c|c|c|c|c|c|c|c|c|c|c|c|c|c|c|}
\hline \multirow{2}{*}{ Source } & \multirow{2}{*}{ Technique } & \multicolumn{3}{|c|}{$\begin{array}{l}\text { Phases - knowledge } \\
\text { elicitation }\end{array}$} & \multicolumn{14}{|c|}{ Chronology and number of citations } \\
\hline & & A & $\mathbf{R}$ & T & ๕ั่ & ¿े & 葱 & $\mid \begin{array}{l}-1 \\
\stackrel{n}{n}\end{array}$ & ב⿱丶万仒 & 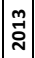 & $\stackrel{\text { ก }}{2}$ & $\stackrel{n}{n}$ & 足 & กิ่ & & 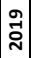 & ָ̊. & 胥 \\
\hline $\begin{array}{l}\text { (Hoffman, 2008), (Zhang et al., 2009), (Tan et al., 2010), (Ting et al., 2011), } \\
\text { (Gavrilova and Andreeva, 2012), (Rosário et al. 2015), (Durso, Kazi and } \\
\text { Ferguson, 2015), (Mohamed, Chakraborty and Dehlinger, 2016), (Leu and } \\
\text { Abbass, 2016), (Grandvallet et al. 2017), (Dorton et al. 2020) }\end{array}$ & Observation & & & & - & $\cdot$ & $\cdot$ & $\cdot$ & $\cdot$ & & & $:$ & $:$ & - & & & - & 11 \\
\hline $\begin{array}{l}\text { (Hoffman, 2008), (Berge et al., 2008), (Zappavigna and Patrick, 2010), } \\
\text { (Stewart Lee and Edwards, 2012), (Xavier et al., 2013), (Rosário et al. 2015), } \\
\text { (Leu and Abbass, 2016), (Brösamle and Hölscher, 2018) }\end{array}$ & Protocol analysi & & & & $:$ & & - & & - & $\cdot$ & & - & $\cdot$ & & - & & & 8 \\
\hline $\begin{array}{l}\text { (Berge et al., 2008), (Abdul-Rahman, Wang e Siong, 2011), (Abdul-Rahman, } \\
\text { Wang e Siong, 2011), (Selwyn and Classen, 2012), (Gavrilova and } \\
\text { Andreeva, 2012), (Compton, 2013), (Rosário et al. 2015), (Leu and Abbass, } \\
\text { 2016) }\end{array}$ & Repertory grid & & & & - & & & : & : & $\bullet$ & & $\bullet$ & $\bullet$ & & & & & 8 \\
\hline $\begin{array}{l}\text { (Selwyn and Classen, 2012), (Leu and Abbass, 2016), (Pattarawan, Brian } \\
\text { and Jignya, 2016), (Grandvallet et al. 2017), (Cerchione and Esposito, 2017), } \\
\text { (Rosso et al., 2018), (Hobballah, et al. 2018) }\end{array}$ & $\begin{array}{l}\text { Semi- structured } \\
\text { interview }\end{array}$ & & & & & & & & - & & & & $\cdots$ & & $\bullet$ & & & 8 \\
\hline $\begin{array}{c}\text { (Hoffman, 2008), (Berge et al., 2008), (Abdul-Rahman, Wang e Siong, 2011), } \\
\text { (Rosário et al. 2015), (Yip and Lee, 2016), (Leu and Abbass, 2016), } \\
\text { (Grandvallet et al. 2017), (Hobballah, et al. 2018) }\end{array}$ & Unstructured interview & & & & : & & & - & & & & - & : & - & - & & & 8 \\
\hline $\begin{array}{l}\text { (Hoffman, 2008), (Berge et al., 2008), (Gavrilova and Andreeva, 2012), } \\
\text { (Compton, 2013),(Rosário et al. 2015), (Brösamle and Hölscher, 2018) }\end{array}$ & Card sorting & & & & $:$ & & & & - & - & & $\cdot$ & & & $\bullet$ & & & 6 \\
\hline $\begin{array}{l}\text { (Xavier et al., 2013), (Rosário et al. 2015), (Durso, Kazi and Ferguson, 2015), } \\
\text { (Leu and Abbass, 2016), (Grandvallet et al. 2017), (Hobballah, et al. 2018) }\end{array}$ & Structured interview & & & & & & & & & - & & $\bullet \bullet$ & - & - & - & & & 6 \\
\hline $\begin{array}{c}\text { (Hoffman, 2008), (Tan et al., 2010), (Gavrilova and Andreeva, 2012), } \\
\text { (Brown et al., 2016), (Leu and Abbass, 2016), (Earl, Mavin, and Kassandra, } \\
\text { 2017). }\end{array}$ & $\begin{array}{l}\text { Talk-aloud ou thinking } \\
\text { aloud ou verbal } \\
\text { protocols }\end{array}$ & & & & - & & - & & - & & & & $:$ & $\bullet$ & & & & 6 \\
\hline $\begin{array}{l}\text { (Hoffman, 2008), (Naweed, 2014), (Durso, Kazi and Ferguson, 2015), (Leu } \\
\text { and Abbass, 2016), (Rosso et al., 2018), (Schnittker et al., 2019), (Okoli, } \\
\text { 2020) }\end{array}$ & $\begin{array}{c}\text { Critical Decision Method } \\
\text { (CDM) }\end{array}$ & & & & - & & & & & & - & - & - & & - & - & - & 7 \\
\hline $\begin{array}{c}\text { (Alonso et al., 2012), (Rosário et al. 2015), (Perez et al., 2015), (Akhavan, } \\
\text { Shahabipour and Hosnavi, 2018), (Hobballah, et al. 2018) }\end{array}$ & Bayesian networks & & & & & & & & - & & & : & & & $:$ & & & 5 \\
\hline $\begin{array}{l}\text { (Kwong and Lee, 2009), (Ting et al., 2011), (Mohamed, Chakraborty and } \\
\text { Dehlinger, 2016), (Nikas et al., 2017), (Akhavan, Shahabipour and Hosnavi, } \\
\text { 2018) }\end{array}$ & Cognitive maps & & & & & - & & - & & & & & - & - & - & & & 5 \\
\hline $\begin{array}{l}\text { (Berge et al., 2008), (Abdul-Rahman, Wang e Siong, 2011), (Alonso et al., } \\
\text { 2012), (Gavrilova and Andreeva, 2012), (Pattarawan, Brian and Jignya, } \\
\text { 2016) }\end{array}$ & Cluster analysis & & & & - & & & - & $:$ & & & & - & & & & & 5 \\
\hline $\begin{array}{c}\text { (Tan et al., 2010), (Selwyn and Classen, 2012), (Mohamed, } \\
\text { Chakraborty and Dehlinger, 2016), (Leu and Abbass, 2016), (Centobelli, } \\
\text { Cerchione and Esposito, 2018) }\end{array}$ & Delphi method & & & & & & - & & - & & & & - & & - & & & 4 \\
\hline $\begin{array}{l}\text { (Tan et al., 2010), (Abdul-Rahman, Wang e Siong, 2011), (Selwyn and } \\
\text { Classen, 2012), (Naweed, 2014), }\end{array}$ & Ground Theory & & & & & & - & - & - & & $\bullet$ & & & & & & & 4 \\
\hline $\begin{array}{c}\text { (Gavrilova and Andreeva, 2012), (Gavrilova and Andreeva, 2012), (Rosário } \\
\text { et al. 2015), (Centobelli, Cerchione and Esposito, 2018) }\end{array}$ & Brainstorming & & & & & & & & $:$ & & & - & & & - & & & 4 \\
\hline $\begin{array}{r}\text { (Selwyn and Classen, 2012), (Gavrilova and Andreeva, 2012), (Pattarawan, } \\
\text { Brian and Jignya, 2016), (Yip and Lee, 2016) }\end{array}$ & Storytelling & & & & & & & & $:$ & & & & $:$ & & & & & 4 \\
\hline (Naweed, 2014), (Durso, Kazi and Ferguson, 2015), (Leu and Abbass , 2016) & Cognitive Work Analysis & & & & & & & & & & - & - & - & & & & & 3 \\
\hline (Gaines, 2013), (Rosário et al. 2015), (Leu and Abbass , 2016) & Production rules & & & & & & & & & $\cdot$ & & $\cdot$ & $\cdot$ & & & & & 3 \\
\hline (Compton, 2013), (Xavier et al., 2013) & $\begin{array}{l}\text { laddering ou laddered } \\
\text { grid }\end{array}$ & & & & & & & & & $:$ & & & & & & & & 2 \\
\hline (Tan et al., 2010), (Brösamle and Hölscher, 2018) & Walkthroughs & & & & & & & & & $\cdot$ & & & & & $\cdot$ & & & 2 \\
\hline (Rosário et al. 2015), (Grandvallet et al. 2017) & Limited information & & & & & & & & & & & $\cdot$ & & - & & & & 2 \\
\hline (Yip and Lee, 2016), (Pattarawan, Brian and Patel, 2016) & Sensemaking & & & & & & & & & & & & $:$ & & & & & 2 \\
\hline (Cairó and Guardati, 2012) & KAMET & & & & & & & & - & & & & & & & & & 1 \\
\hline (Yip and Lee, 2016) & $\begin{array}{l}\text { Group Reflection and } \\
\text { Inquiry Protocol (GRIP) }\end{array}$ & & & & & & & & & & & & - & & & & & 1 \\
\hline (Rosso et al., 2018) & Hierarchical Task & & & & & & & & & & & & & & - & & & 1 \\
\hline (Kwong and Lee, 2009) & Aggregate cognitive map & & & & - & & & & & & & & & & & & & 1 \\
\hline (Léger and Naud, 2009) & Statechart diagram & & & & & - & & & & & & & & & & & & 1 \\
\hline (Rosário et al. 2015) & Triadic comparison & & & & & & & & & & & - & & & & & & 1 \\
\hline (Yazdi, 2019) & Fault Tree Analysis (FTA) & & & & & & & & & & & & & & & $\bullet$ & & 1 \\
\hline
\end{tabular}

(2021).

Legend: A - Acquisition / R - Representation / T - Transfer. Source: Authors 


\section{International Journal of Knowledge Engineering and Management,}

Florianópolis, v. 9, n. 25, p.93 - 126, 2020.

- ISSN 2316-6517 •

- DOI: 1047916 •

Knowledge elicitation techniques may be represented somewhere between the three phases of the knowledge elicitation process. The seventh research topic discusses the complementary or hybrid adoption of the techniques, given its limitations when adopted exclusively (Hao Jia et al., 2017). The researches that adopted as a strategy the complementary use of knowledge elicitation techniques are detailed in Table 6.

Table 6 - Evidence of complementarity between techniques

\begin{tabular}{|l|l|}
\hline \multicolumn{1}{|c|}{ Source } & Complementary techniques \\
\hline Kwong and Lee, 2009 & Cognitive map an Aggregate cognitive map \\
\hline $\begin{array}{l}\text { Abdul-Rahman, Wang and Siong, } \\
2011\end{array}$ & Repertory grid and Cluster analysis \\
\hline Selwyn and Classen, 2012 & Storytelling and Grounded theory \\
\hline Naweed, 2014 & $\begin{array}{l}\text { Cognitive Work Analysis (CWA), Critical Decision } \\
\text { Method (CDM) and Ground Theory }\end{array}$ \\
\hline Rosário et. al, 2015 & $\begin{array}{l}\text { Unstructured interview, Card sorting, Limited } \\
\text { information, Observation method, Protocol analysis and } \\
\text { Production rules }\end{array}$ \\
\hline Grandvallet et al. 2017 & Semi- structured interview and Limited information \\
\hline Yip and Lee, 2016 & $\begin{array}{l}\text { Unstructured interview, Sensemaking and Group } \\
\text { Reflection and Inquiry Protocol (GRIP) }\end{array}$ \\
\hline Rosso et al., 2018 & $\begin{array}{l}\text { Critical Decision Method (CDM) and Hierarchical Task } \\
\text { Analysis }\end{array}$ \\
\hline $\begin{array}{l}\text { Akhavan, Shahabipour and } \\
\text { Hosnavi, 2018 }\end{array}$ & Cognitive maps and Bayesian belief networks \\
\hline $\begin{array}{l}\text { Pattarawan, Brian and Jignya, } \\
\text { 2016 }\end{array}$ & Storytelling and Semi- structured interview. \\
\hline
\end{tabular}

Source: Authors (2021)

\section{Discussion and future searches}

Assuming the need to provide instruments for the knowledge engineer, knowledge elicitation techniques play an important role in this context. Based on the classification of the most cited techniques in the literature according to Table 5, as well as considering the phases of the knowledge elicitation process. Based Vásquez-Bravo et al. (2014), the ways in which the techniques hypothetically can be integrated were projected. 


\section{International Journal of Knowledge Engineering and Management,}

Florianópolis, v. 9, n. 25, p.93 - 126, 2020.

- ISSN 2316-6517 •

- DOI: 1047916 •

\subsection{Knowledge acquisition phase}

Durso, Kazi and Ferguson (2015), Mohamed, Chakraborty and Dehlinger (2016), Leu and Abbass (2016) and Grandvallet et al. (2017), indicate that the observation technique can be used to identify the strategies adopted. It can also be implemented to study motor skills or automated procedures to identify activities involved in solving a problem, as well as its constraints. The observation technique can be adopted as a form of prior learning of the knowledge engineer so that it can enhance their understanding of the process to be elicited. In this sense, it is recommended to use interview techniques after the observations, employing them, according to the objectives of the elicitation, such as the Critical Decision Method (CDM), pointed out by Rosso et al. (2018) and Schnittker et al. (2019), as an alternative structured interview technique. Semi-structured and unstructured interviewing techniques can also be applied according to elicitation objectives, for example, repertory grid techniques, Card sorting, Brainstorming, Storytelling, Limited information, and Cognitive maps can be adopted in a complementary and concomitant manner of interviewing techniques. Among the aforementioned techniques, the repertory grid stands out, pointed out as an emerging alternative of tacit knowledge elicitation based on the indications of Abdul-Rahman, Wang and Siong (2011). According to the authors, the repertory grid technique was designed to extract the interviewee's traits and objects and classify them into categories through the interviewer's inference. This technique allows the elicitation of mental constructs, which represent the mental patterns formed during the lived experience. The premises that constitute the practical application of the repertory grid technique are: i) to understand the structure of the constructs, ii) to classify the elements as their degree of mental hierarchy; iii) to infer the relationship of the constructs and the elements. The structure of personal constructs may be understood using bipolar measurement scales. The inference about the elements and the constructs will occur in the analysis of knowledge leveling among the knowledge holders, where the elements are represented by the problem situation variables and the constructs represented by the measurement scale. 


\section{International Journal of Knowledge Engineering and Management,}

Florianópolis, v. 9, n. 25, p.93 - 126, 2020.

- ISSN 2316-6517 •

- DOI: 1047916 •

\subsection{Knowledge representation and transfer phase}

The literature that approaches tacit knowledge in a perspective that involves its articulation, discusses the capture and codification of knowledge, for example, explored in Lazaric et al. (2003) and Oguz and Elif (2011). Knowledge is the modeling of the results of knowledge acquisition with the objective of codifying it. At this stage it is considered that knowledge will be articulated, a theme pointed out as the research direction by Lazaric et al. (2003), Oguz and Elif (2011) and Krishna and Busch (2012), adopted in the systematic review as one of the discussion elements, considering the sequencing of the knowledge elicitation process. On based on Vásquez-Bravo et al. (2014), the following are described techniques that can be employed in the phase of representation and transfer of knowledge and its articulations.

Based on the results of the repertory grid application, exposed in the previous section, the classification of variables as their degree of mental hierarchy can be performed using the Cluster analysis technique based on Abdul-Rahman, Wang and Siong (2011). The authors adopted the techniques complementarily, as shown in Table 6. The role of the cluster analysis technique is to organize the data semantically establishing the links between the main variables verbalized by the knowledge holders. In this context, integration between Repertory Grid and Cluster analysis can be recommended, for example, it can be found in Rosário et al. (2022). Based on Neil (1990), the use of dendrograms is suggested as a representation of links between the variable Thus the clusters will be represented by dendrograms, as a cognitive map, found in Nikas et al. (2017) and Akhavan, Shahabipour and Hosnavi (2018). The objectives of analyzing knowledge holders' mental patterns are twofold: I) to analyze the degree of similarity in knowledge between them, for example, as an Aggregate cognitive map, found in Kwong \& Lee (2009); and II) to establish a degree of hierarchy between the variables. Based on the knowledge elicitation process, until the cluster analysis phase, it will be possible to establish the relationship of the occurrences of the conditional state variables, due to the links established by the dendrograms. The Bayesian Belieff Network (BBN) can be modeled based on the dendrograms, for example, it can be found in Rosário et al. (2022). BBN consists of a statistical model that represents a set of variables and their causal relationships as a function of their dependency links, and as a consequence, assists in decision making. For the purposes of the systematic review, the 
Bayesian network represents a mechanism of knowledge representation and transference among knowledge holders, since it allows the realization of probabilistic simulations after modeling, based on the decision making elicitation, promoting the articulation of knowledge sharing.

\section{Conclusion}

The systematic review explored the factors that impact the tacit knowledge elicitation process. It was structured based on the indications of future works in a theoretical scope, which allowed a systematic exposure of the scope and complexity of the knowledge conversion process from tacit to explicit. It has been decided to broaden the debate around the process of converting individual epistemological tacit knowledge to organizational ontological explicit knowledge by establishing some alternatives for the empirical use of knowledge elicitation techniques employed in an integrated manner, given the indications of their fragility when adopted alone. A relevant point of the systematic review had been to propose the articulation of knowledge after the acquisition process, as there are indications in the literature about the need to approach this perspective. The paradigm of the dimension of knowledge was also a point discussed by the review. However, far from being exhausted, there was an indication of the need for future works that solidify the codification of the verbalization of knowledge through the analysis of linguistic patterns, a way to rediscuss the paradigm of the dimension of knowledge instituted by Polanyi. One of the factors that may help in this context is the projection of interviews with knowledge holders in order to stimulate the memory of episodic memories as a means of identifying tacit knowledge. Finally, the integration of knowledge elicitation techniques and the factors that involve this process was the central discussion of the systematic review, thus contributing to the scientific community when exposing the modeling alternatives of tacit knowledge as tactical knowledge-oriented propositions. 


\section{International Journal of Knowledge Engineering and Management,}

Florianópolis, v. 9, n. 25, p.93 - 126, 2020.

- ISSN 2316-6517 •

- DOI: 1047916 •

\section{References}

Abdul-Rahman, Wang, H., Siong, C. (2011). Repertory grid technique in the development of Tacit-based Decision Support System (TDSS) for sustainable site layout planning. Automation in Construction, p. 818-829.

Akhavan, P., Shahabipour, A., Hosnavi, R. (2018) "A model for assessment of uncertainty in tacit knowledge acquisition", Journal of Knowledge Management, Vol. 22 Issue: 2, p.413-431.

Alonso, F., Martínez, L., Pérez, A., Valente, J. P. (2012). Cooperation between expert knowledge and data mining discovered knowledge: Lessons learned. Expert Systems with Applications, 39(8), 7524-7535.

Berge, P.R., Adde, G. Espinosa, O. Stavdahl. (2008). ENIGMA - Enhanced interactive general movement assessment. Expert Systems with Applications, vol.34, p.26642672.

Boell, S., Cecez-Kecmanovic, D. (2015). On being 'systematic' in literature reviews in IS. Journal of Information Technology. Vol. 30, p. 161-173.

Brand, A. (1998) "Knowledge Management and Innovation at 3M", Journal of Knowledge Management, Vol. 2 Issue: 1, p.17-22.

Brösamle M.; Hölscher, C. (2018). Approaching the architectural native: a graphical transcription method to capture sketching and gesture activity. Design Studies, vol. 56, p. 1-27.

Brown, R., Bruza, P., Heard, W., Mengersen, K., \& Murray, J. (2016). On the (virtual) getting of wisdom: Immersive 3D interfaces for eliciting spatial information from experts. Spatial Statistics, 18, 318-331. 


\section{International Journal of Knowledge Engineering and Management,}

Florianópolis, v. 9, n. 25, p.93 - 126, 2020.

-ISSN 2316-6517 •

- DOI: 1047916 •

Cairó O., Guardati S. (2012). The KAMET II methodology: Knowledge acquisition, knowledge modeling and knowledge generation. Expert Systems with Applications, vol. 39 , p. 8108-8114.

Carayannis, E. G. (1999), "Fostering synergies between information technology and managerial and organizational cognition: the role of knowledge management", Technovation, Vol. 19 No. 4, p. 219-231.

Castaneda D. I., Manrique L. F., Cuellar S. (2018) "Is organizational learning being absorbed by knowledge management? A systematic review", Journal of Knowledge Management, Vol. 22 Issue: 2, p. 299-325.

Centobelli, P., Roberto, C., Emilio, E. (2018). Aligning enterprise knowledge and knowledge management systems to improve efficiency and effectiveness performance: A three-dimensional Fuzzy-based decision support system. Expert Systems With Applications, vol. 91, p. 107-126.

Cerchione, R., Esposito, E. (2017). Using knowledge management systems: A taxonomy of SME strategies. International Journal of Information Management. vol.37, p. 15511562.

Coffey, J. W., Hoffman, R. R. (2003) "Knowledge modeling for the preservation of institutional memory", Journal of Knowledge Management, Vol. 7 Issue: 3, p. 38-52. Compton Paul. (2013). Situated cognition and knowledge acquisition research. Int. J.Human-Computer Studies, vol. 71, p. 184-190.

Durso, F. T., Kazi, S., Ferguson, A. N. (2015). The Threat-Strategy Interview. Applied Ergonomics, vol.47, p. 336-344.

Ebrahim, R. (2006) "Knowledge management: securing the future", Journal of Knowledge Management, Vol. 10 Issue: 4, p. 145-156 


\section{International Journal of Knowledge Engineering and Management,}

Florianópolis, v. 9, n. 25, p.93 - 126, 2020.

-ISSN 2316-6517 •

- DOI: 1047916 •

Feldon, D. F., Franco, J., Chao, J., Peugh, J., \& Maahs-Fladung, C. (2018). Self-efficacy change associated with a cognitive load-based intervention in an undergraduate biology course. Learning and Instruction, 56, 64-72.

Flanagan, T., Eckert, C.; Clarkson, P.J., (2007). Externalising tacit overview knowledge: A model-based approach to supporting design teams. AI EDAM: Artircial Intelligence for Engineering Design, Analysis, and Manufacturing, 21(3), p. 227-242.

Gàbor, A; Barna, G. (1988). Knowledge-based system for supporting statistical database Management. Knowledge-based Systems. 1(5), p. 279-284.

Garcia-Perez, A., Shaikh, S. A., Kalutarage, H. K., \& Jahantab, M. (2015). Towards a knowledge-based approach for effective decision-making in railway safety. Journal of knowledge Management.

Garg, H., Monica, R., Sharma S. P., Yashi V. 2014. Intuitionistic fuzzy optimization technique for solving multi-objective reliability optimization problems in interval environment, Expert Systems with Applications, vol.41, p. 3157-3167

Gavrilova, T., Andreeva, T. (2012) "Knowledge elicitation techniques in a knowledge management context", Journal of Knowledge Management, Vol. 16 Issue: 4, p. 523-537.

Grandvallet, C., Pourroy, F., Prudhomme, G., \& Vignat, F. (2017). Testing three techniques to elicit additive manufacturing knowledge. In Advances on Mechanics, Design Engineering and Manufacturing (pp. 281-288). Springer, Cham.

Guérin, F. (2001) Comprendre le travail pour le transformer, la pratique de l'ergonomie, Edgard Blucher Itda.

Hanafizadeh, P., Ghamkhari, F. (2019). Elicitation of Tacit Knowledge Using Soft Systems Methodology, Systemic Practice and Action Research, Vol. 32, p. 521-555. 


\section{International Journal of Knowledge Engineering and Management,}

Florianópolis, v. 9, n. 25, p.93 - 126, 2020.

-ISSN 2316-6517 •

- DOI: 1047916 •

Hao, J.. Zhao Q., Yan Y., Wang G. (2017). A Review of Tacit Knowledge: Current Situation and the Direction to Go. International Journal of Software Engineering and Knowledge Engineering, Vol. 27, No. 5, p. 727-748

Hoffman, R. (2008), "Human Factors Contributions to Knowledge Elicitation Robert", Human Factors: The Journal of the Human Factors, Vol. 50, No. 3, p. 481-488.

Krishna, V.; Busch P., (2012). "Tacit knowledge: review and possible research directions", Journal of Knowledge Management, Vol. 16 Iss. 2 pp. 357-372.

Kwong, E., W. B. Lee, (2009) "Knowledge elicitation in reliability management in the airline industry", Journal of Knowledge Management, Vol. 13 Issue: 2, p. 35-48.

Laksch, J. S.; Borsato M.(2019) Method for digital evaluation of existing production systems adequacy tochanges in product engineering in the context of the automotive industry, Advanced Engineering Informatics, Vol. 42.

Lazaric, N., Mangolte, P.A. and Massue, M.L. (2003), "Articulation and codification of collective know-how in the steel industry: evidence from blast furnace control in France", Research Policy, Vol. 32 No. 10, p. 1829-47

Léger B., Olivier N. (2009). Experimenting statecharts for multiple experts knowledge elicitation in agriculture. Expert Systems with Applications, vol.36, p. 11296-11303.

Leplat, J.; Rasmussen, J., (1984). Analysis of human errors in industrial. Accid. Anal \& Prev., 16(2), p. 77-88.

Leu G., Abbass H. (2016). A multi-disciplinary review of knowledge acquisition methods: From human to autonomous eliciting agents. Knowledge-Based Systems, vol. 105, p. 1 22. 


\section{International Journal of Knowledge Engineering and Management,}

Florianópolis, v. 9, n. 25, p.93 - 126, 2020.

- ISSN 2316-6517 •

- DOI: 1047916 •

Leyer, M., Schneider, C., Claus, N. (2016). Would you like to know who knows? Connecting employees based on process-oriented knowledge mapping. Decision Support Systems, vol. 87, p. 94-104.

Li Dacheng, Jinji Gao (2010). Study and application of Reliability-centered Maintenance considering Radical Maintenance, Journal of Loss Prevention in the Process Industries, vol. 23, p. 622-629

Liu Hu-Chen, Jian-Xin Y., Xiao-Jun F. e Ging-lian Lin, (2014). Failure mode and effects analysis using $D$ numbers and grey relational projection method. Expert Systems with Applications, vol. 41, p. 4670-4679.

Margaryan A., Littlejohn A., Stanton N. A., (2016). "Research and development agenda for Learning from Incidents", Safety Science, Vol. 99, p. 5-13.

Mohamed, M. A., Chakraborty, J., Dehlinger, J. (2016). Trading off usability and security in user interface design through mental models. Behaviour \& Information Technology, p. 493-516.

Moher D., Cook D. J., Eastwood S., Olkin I., Rennie D., \& Stroup D. F. (1999). Improving the quality of reports of meta-analyses of Randomised controlled trials: the QUOROM statement. Quality of Reporting of Meta-analyses, The Lancet, Vol. 354, p. 1896-1900.

Moher D., Liberati A., Tetzlaff J., Altman D. G. (2009). The PRISMA Group. Preferred Reporting Items for Systematic reviews and Meta-Analyses: the PRISMA statement. Journal of Clinical Epidemiology, Vol 62, p. 1006-1012.

Naweed A. (2014). Investigations into the skills of modern and traditional train driving. Applied Ergonomics, vol.45, p.462-470.

Neil, A. (1990). "Repertory Grid Technique in Employee Selection", Personnel Review, Vol. 19 Issue: 3, p. 9-15. 


\section{International Journal of Knowledge Engineering and Management,}

Florianópolis, v. 9, n. 25, p.93 - 126, 2020.

-ISSN 2316-6517 •

- DOI: 1047916 •

Nikas, A., Haris, D., Jenny, L., Rocío, A. T., Vasileios, C., Wytze, G. (2017). "Managing stakeholder knowledge for the evaluation of innovation systems in the face of climate change", Journal of Knowledge Management, Vol. 21 Issue: 5, p. 1013-1034.

Nikulina I.E., Khomenko I.V, (2015). Cognitive management: theory and practice in the organization, Procedia - Social and Behavioral Sciences, Vol. 166 , p. $441-445$

Nonaka, I. \& Von Krogh, G., (2009), "Perspective--Tacit Knowledge and Knowledge Conversion: Controversy and Advancement in Organizational Knowledge Creation Theory", Organization Science, Vol.20 No.3, p. 635-652.

Nonaka, I. (1991), "The knowledge-creating company", Harvard Business Review, Vol. 69 No. 6, p. 96-104.

Nonaka, I. and Takeuchi, H. (1995), The Knowledge-creating Company: How Japanese Companies Create the Dynamics of Innovation, Oxford University Press, Oxford.

Nonaka, I., (1994), "A dynamic theory of Organization Knowledge Creation", Organization Science, Vol.5 No.1, p. 14-37.

Nonaka, I., Byosiere, P. \& Borucki, C.C., (1994), "Organizational Knowledge Creation Theory: A First Comprehensive Test", Internation Business Review, Vol. 3, No. 4, p. 337-351.

Nonaka, I., Umemoto, K. \& Senoo, D., (1996). "From information processing to knowledge creation: A paradigm shift in business management", Technology in Society, Vol. 18, No 2, p. 203-218.

Nonaka, I.; Von Krogh, G., (2009). Perspective--Tacit Knowledge and Knowledge Conversion: Controversy and Advancement in Organizational Knowledge Creation Theory. Organization Science, 20(3), p. 635-652. 


\title{
International Journal of Knowledge Engineering and Management,
}

\author{
Florianópolis, v. 9, n. 25, p.93 - 126, 2020. \\ - ISSN 2316-6517 • \\ - DOI: 1047916 •
}

Oguz F., Elif, S. (2011)."Mystery of the unknown: revisiting tacit knowledge in the organizational literature", Journal of Knowledge Management, Vol. 15 Iss 3 p. 445 - 461

Oliva, G., Medina, N., Weber, P., Jung, B. (2015). Industrial system knowledge formalization to aid decision makingin maintenance strategies assessment. Engineering Applications of Artificial Intelligence, vol. 37, p. 343-360.

Pattarawan, P., Brian D; Janz, J. P. (2016) "Towards a better understanding of system analysts' tacit knowledge: A mixed method approach", Information Technology \& People, Vol. 29 Issue: 1, p. 69-98.

Plant, K. L. Stanton N. A. (2015). Identifying the importance of perceptual cycle concepts during critical decision making in the cockpit, Procedia Manufacturing, Vol. 3, 2410-2417

Plessis, M. (2007) "Knowledge management: what makes complex implementations successful?", Journal of Knowledge Management, Vol. 11 Issue: 2, p. 91-101,

Polanyi, M. (1966). The Tacit Dimension, London: Routledge \& Kegan Paul.

Preiss Kenneth J., (2000) "A two-stage process for eliciting and prioritising critical knowledge", Journal of Knowledge Management, Vol. 4 Issue: 4, p. 328-336

Rosário, C. R. do, Kipper L. M., Frozza R., Bueno B. M. (2015). Modeling of tacit knowledge in industry: Simulations on the variables of industrial processes. Expert Systems With Applications, vol. 42, p. 1613-1625.

Rosário, C. R., Amara F. G., Kuffel F. Jose M., Kipper L. M., Frozza R.Using Bayesian belief networks to improve distributed situation awareness in shift changeovers: A case study, Expert Systems with Applications, Vol. 188, 2022.

Rosso, G., Frisiello, A., Trizio, M., Mosso, C. O., Bazzani, M. (2018). Learning from professionals: exploring cognitive rehabilitation strategies for the definition of the functional requirements of a telerehabilitation platform. Computers in biology and medicine, 95, 288-297. 


\section{International Journal of Knowledge Engineering and Management,}

Florianópolis, v. 9, n. 25, p.93 - 126, 2020.

- ISSN 2316-6517 •

- DOI: 1047916 •

Sasson J. R., Ian D. (2006) "A conceptual integration of performance analysis, knowledge management, and technology: from concept to prototype", Journal of Knowledge Management, Vol. 10 Issue: 6, p. 81-99

Schnittker, R.; Marshall, S. D.; Horberry, T.; Young, K. (2019). Decision-centred design in healthcare: The process of identifying a decision support tool for airway management. Applied Ergonomics, vol. 77, p. 70-82

Selwyn, C., Whyte, G. (2012). "Using storytelling to elicit tacit knowledge from SMEs", Journal of Knowledge Management, Vol. 16 Issue: 6, p.950-962

Suchman, L.A. (1987). Plans and situated actions: The problem of human-machine communication. New York: Cambridge University Press.

Ting S.L.; Wang W.M.; Y.K; Tse, W.H. Ip. (2011) "Knowledge elicitation approach in enhancing tacit knowledge sharing", Industrial Management \& Data Systems, Vol. 111 Issue: 7, p. 1039-1064.

Ulrich H. (2004). Semi-quantitative fault tree analysis for process plant safety using frequency and probability ranges, Journal of Loss Prevention in the Process Industries, vol. 17 p. 339-345.

Vásquez-Bravo, Di. M. I., Segura S. M. F., Domínguez M. Amescua, A. (2014), "Knowledge management acquisition improvement by using software engineering elicitation techniques", Computers in Human Behavior, Vol. 30, p. 721-730.

Wagne, W.P.; J. Otto, Q; Chung, .B. (2002). Knowledge acquisition for expert systems in accounting and financial problem domains, Knowledge-Based Systems, vol. 15, p. $439-447$ 


\section{International Journal of Knowledge Engineering and Management,}

Florianópolis, v. 9, n. 25, p.93 - 126, 2020.

- ISSN 2316-6517 •

- DOI: 1047916 •

Xavier, D., Morán, F., Fuentes-Fernández, R., \& Pajares, G. (2013). Modelling knowledge strategy for solving the DNA sequence annotation problem through CommonKADS methodology. Expert Systems with Applications, 40(10), 3943-3952.

Yip J. Y. T., Lee R. W. B. (2016). Knowledge elicitation practices for organizational development intervention. Knowledge Management Research \& Practice. p. 1-14.

Zappavigna M., Patrick, J. (2010). Eliciting tacit knowledge about requirement analysis with a Grammar-targeted Interview Method (GIM). European Journal of Information Systems, vol. 19, p. 49-59.

Zhang W.Y., M. Cai, J. Qiu \& J.W. Yin. (2009). Managing distributed manufacturing knowledge through multi-perspective modelling for semantic web applications. International Journal of Production Research, vol. 47, 26, p. 6525-6542.

Zhou, Y.J., (2004). An empirical study of shop floor tacit knowledge acquisition in Chinese manufacturing enterprises. International Journal of Industrial Ergonomics, 34(4), p. 249-261. 